\title{
Prediction Models for Distortions and Residual Stresses in Thermoset Polymer Laminates: An Overview
}

\author{
Morteza Abouhamzeh*D, Jos Sinke and Rinze Benedictus \\ Faculty of Aerospace Engineering, Delft University of Technology, Kluyverweg 1, 2629 HS Delft, \\ The Netherlands; J.sinke@tudelft.nl (J.S.); R.Benedictus@tudelft.nl (R.B.) \\ * Correspondence: m.abouhamzeh@tudelft.nl or morteza.ab@gmail.com; Tel.: +31-15-2788673; \\ Fax: +31-15-2781151
}

Received: 28 June 2019; Accepted: 27 August 2019; Published: 11 October 2019

\begin{abstract}
This paper reviews predictive models developed for the development of residual stresses and shape distortions during the manufacturing of thermoset polymeric/composite materials. Different sources that produce residual stresses and shape changes in the laminated panels are described and reviewed. An overview is presented on the characterisation and predictions of the phenomena resulting in residual stresses. The focus will be on the models accounting for the parameters during the cure cycle of the thermoset composite materials published in the literature from 2005 until 2018. The material types covered here range from thermoset adhesives, full composites, and fibre metal laminates. Furthermore, selected works are reviewed on the reduction of the shape changes and residual stresses of composites and fibre metal laminates consisting of thermoset polymers.
\end{abstract}

Keywords: thermoset; composite; hybrid; adhesive; cure cycle; model; residual stresses; distortions

\section{Introduction}

Composite structures are used in aerospace and automotive applications due to their high strength and stiffness-to-weight ratios. The manufacturing processes consist of impregnation of fibres with resin, layup of the laminae into laminates, and finally, curing of the resin.

The exact process of manufacturing of composite materials depends on the fibre architecture, fibre lengths, and specifically the type of polymer used as the matrix. Matrix polymers can be generally divided into thermosets and thermoplastics. Thermoset polymers are cured at elevated temperatures with crosslinking of the polymer. They are more brittle than thermoplastics and not able to be thermally recycled, so they are cured and shaped to their final geometry. On the other hand, thermoplastics can be reheated, melted, and reshaped but have much higher viscosity. Thermoplastics can be welded, and their toughness, storage life, and chemical resistance are high. Since thermoset composites are used predominantly in aerospace primary structures due to their high strength, this type of composite will be considered in more detail in this paper.

In the following sections, different aspects of the manufacturing process of thermoset composite laminates are discussed. The developed modelling procedures presented in the literature are reviewed for full composites and fibre metal laminates based on thermoset polymer constituents.

\section{The Manufacturing Process of Thermoset Composites}

From the 1970s, studies have been carried out on the curing process of thermoset composite materials and the resulting residual stresses and shape distortions [1-11]. Autoclave processing, using pre-impregnated uniaxial prepreg, is a common manufacturing method to produce high- 
performance fibre-reinforced composite laminates. The cure cycle is divided into three parts: Heating to the cure temperature, curing isothermally (at constant cure temperature), and cool-down to ambient temperature. Note that the isothermal cure part can be done in one or two stages [12]. In a two-step cure cycle, the material is held at the dwell temperature for about $1 \mathrm{~h}$. The temperature is increased to the second temperature level and held constant for the remaining isothermal cure period $(2-8 \mathrm{~h})$. The purpose of the dwell period is to allow gases (entrapped air, water, or volatiles) to escape the matrix material and to allow the matrix to flow, facilitating compaction of the part. Thus, the viscosity must be low during the dwell period. Typical viscosity versus temperature profiles of polymer matrices show that as the temperature is increased, the viscosity of the polymer decreases until a minimum. As the temperature is increased further, the polymer begins to cure rapidly, resulting in a fast viscosity increase. The first dwell temperature must be chosen judiciously to allow the viscosity of the resin to be low while keeping the cure to a minimum. Isothermal viscosity versus time profiles are useful in determining the pot life of the polymer: The maximum length of time at a specific temperature for the polymer to maintain a prescribed viscosity for the handling of the resin. A certain minimum temperature must be reached before the crosslinking reaction speeds up. It is here that the strength and related mechanical properties of the composite are developed. Demands for increased performance have recently led to the development of several high-temperature (for instance, above $100{ }^{\circ} \mathrm{C}$ ) resins. These high-temperature resins retain good mechanical properties at elevated service temperatures. However, one of the problems encountered when processing at higher temperatures is the increased residual stresses.

Some portions of the produced residual stresses are released and create shape deviations (distortions) and some remain as residual stresses. To get the part within the pre-set dimensional tolerances, geometrical compensation of the tool is necessary. Curing-induced stresses may reduce the load capacity and the fatigue life of the product. The shape deviations may result in extra assembly forces producing internal forces and stresses.

With the correct prediction of these responses in the design phase, automating the manufacturing process including assembly will be improved and this will be a great opportunity for the industry. In this section, different mechanisms and factors leading to residual stress and dimensional changes in composite panels are discussed and the related literature is reviewed.

\section{Types and Sources of Distortion and Residual Stress during the Curing Processing of Thermosets}

The distortions can start from different sources that can be thermoelastic (reversible) or nonthermoelastic (non-reversible). Radford and Rennick in 2000 [13] and Wisnom in 2006 [14] well defined these mechanisms, which can be explained and separated as follows.

\subsection{Anisotropy}

Anisotropy, or different directional properties in the layers of the orthotropic material, plays a significant role in the following phenomena:

- Polymerisation (reactions) and chemical shrinkage

During processing of thermoset composites, the resin transforms from a viscous fluid of monomers first to a rubbery state and then to a cross-linked network. During this network formation, the free space occupied by the polymer molecules is reduced, and this causes a chemical shrinkage, which is usually referred to as cure shrinkage. The other important change in the thermoset polymer (principally acting as the adhesive between the fibres and metal sheets) is the evolution of stiffness. This means that the E-modulus or stiffness of the polymer increases while it is solidifying during the polymerisation process. The extent of the cure reactions is described by the degree of cure, which is quantified as the fraction of heat generated to that moment relative to the total heat generated through the complete cure. Some researchers have assumed and observed linear relation between the volume change due to chemical shrinkage and degree of cure $(q)$ [15-18]. The two latter papers model the curing process and 
measure the evolution of shape and volumetric changes caused by chemical and thermal shrinkage. In the following sections, different works relating to the cure modelling of the composite are reviewed.

In a paper by Kelly et al. in 1996 [19], the effect of chemical shrinkage on the residual stress and warpage of moulding compounds used in plastic encapsulated integrated circuit packages are determined to be as high as $70 \%$ in volume. In this way, they have concluded that convenient predictive models that account only for the thermal source in cool-down truly underestimate the results for distortions or residual stresses.

- Thermal contraction (during cool-down)

During heat-up and cool-down, thermal expansion/contraction occurs in the material constituents. Since fibres and matrices have different thermal expansion coefficient and stiffness, these mismatches cause residual stresses. This is the most dominant mechanism in the production of residual stresses in laminated structures $[1,2]$.

\subsection{Fibre Volume Fraction (Material Property) Gradient}

Volume fraction gradient arises because of the resin bleeding from one side of the part, i.e., the vacuum bag side $[13,20]$. Therefore, this effect is important when resin bleed is present in the manufacturing of a composite laminate. It is noted here that there will be no volume fraction gradients through the thickness of laminates made from prepreg layers without any resin bleeding [21].

\subsection{Tool-Part Interaction (Stress Gradient)}

Even in thin, flat, and balanced (symmetric) laminates that are manufactured on a flat tool (mould), warpage would occur after cure if the mould material has a different Coefficient of Thermal Expansion (CTE) from the composite [22]. During processing, as the prepreg is heated under pressure, the fibres that are closest to the mould are clamped against the mould surface by the processing pressure and, therefore, can be stretched by the mould. The stretched layer develops residual tensile stress when the part cools down after cure. When the part is removed from the mould, the strain is equilibrated across the laminate thickness and the part warps concave down. Besides CTE mismatch, the degree of mould stretching depends on the mould surface roughness, cure temperature, and the applied pressure during cure [23].

Under the vacuum pressure, shear stresses are generated at the mould-laminate interface during various phases of the cure cycle. Cho et al. in 1998 [24] studied different factors like the thermo-mechanical properties of the tool-laminate interface, influencing the distortion shapes. It was shown by Fernlund et al. in 2002 [25] that if proper material models are used to represent the stress transfer between the tool and the part together with a large deformation modelling, accurate results can be obtained using finite element modelling, compliant to experiments. Twigg et al. in 2003 [26] investigated the shear stress development at the interface between the tool and laminate. Complete cure cycle was evaluated in this respect with eight strain gauges placed on the aluminium tool, six oriented longitudinally and two transversely. Both sticking and sliding conditions occur in the cure cycle, and the shear stress at which the parts slide $\left(\tau_{\text {sliding }}\right)$ is dependent on the degree of cure and the pressure. Therefore, the cure cycle parameters can influence the amount of residual stress and the final shape. The same authors, in 2004 [27], carried out an experimental survey on the effects of part aspect ratio and processing conditions. The cure pressure and the length and thickness of the laminate affected the warpage the most. In a companion paper [28], they studied the effects of different parameters in the tool-part interaction, numerically. They concluded that both part-tool shear stress and in-plane stress distribution in the part (laminate) are important to consider. Similar work has been done by Ersoy et al., in 2005 [22], in which the frictional shear stresses between prepreg layers and the prepreg-tool interface were experimentally measured versus the degree of cure. Similar experimental work was carried out by Kaushik and Raghavan in 2010 [29], who measured the static and dynamic coefficients of friction between the mould and the laminate. Different parameters were considered 
including the pressure, degree of cure, and the temperature ramp rate on the frictional behaviour. Their measurements were used along with a 3-D finite element model (Zeng and Raghavan in 2010 [30]) using ABAQUS subroutines to develop a process model to study this mechanism of distortion. In 2011, Kappel et al. [23] presented a semi-analytical simulation based on shell elements and measured the warpage of some test specimens, made from two common prepreg systems made of different epoxy systems of Hexcel. They focused on the warpage of the specimens caused by the tool-part interaction and used their calculations to compensate for the warpage by revising the tool surface geometry.

\section{Research on Cure-Cycle-Induced Residual Stresses}

In this section, the works investigating the stress build-up during cure and cool-down are reviewed. As an early and highly cited work in the literature, Hahn and Pagano in 1975 [1] simulated the curing process. They assumed that at the start of the cool-down stage, the material is in the stress-free state. They claim that the residual stresses due to chemical shrinkage of the matrix will disappear due to the viscoelastic relaxation. Therefore, they state that after this stage, no considerable residual stress remains in the matrix, so the cure part does not need to be considered. They used incremental constitutive equations in conjunction with temperature-dependent (nonlinear) material properties. A method of curing stress analysis was formulated based on total thermal strains for resin matrix composites. The method decomposes the total strain into mechanical and thermal parts and the material behaves elastically with temperature-dependency, i.e., elastic compliances and thermal strains varied with temperature.

It should be noted that the modelling approaches in which only the cool-down process is considered for estimation of residual stresses and the resulting distortions choose the Tcure as the starting point to calculate the temperature gradient in the cure cycle.

Hahn continued his work in 1976 [2] using a linear elastic approach for the prediction of residual strains from fabrication and how moisture contributes to the residual stresses, and compared these with some experiments. He stated, in contrast to their claim in their paper in 1975 [1], that the stress-free temperature is lower than the cure temperature.

In 1979, Weitsman [4] calculated the thermal residual stresses within cooling from the cure temperature. He accounted for the temperature dependence of properties and the viscoelastic response. Comparisons with linear elasticity indicated that viscoelastic relaxation might reduce the residual stresses by about $20 \%$. So only the cool-down phase was modelled and the material model (behaviour) was linear viscoelastic.

In 1988, Favre [31] presented the first review of works done up to that date on the development of residual stresses in composites for both thermoplastic and thermoset resin types. In 1989, Kim and Hahn [32] studied the process in which residual stresses develop during processing of a thermoset (graphite/epoxy) composite. They monitored the laminate deflection (see Figure 1) during intermittent curing of a non-symmetric cross-ply laminate. Mechanical properties were indeed measured as functions of the cure time. They stated that for residual stresses after complete cure, linear elastic predictions are adequate, provided that the change in the matrix modulus is accounted for in the analysis. They investigated the complete cure cycle and observed that residual stress and warpage are important after the gel point. Therefore, we can see that the stress-free temperature (which in their case was near the cure temperature) has to be known to calculate the warpage and residual stresses either when an elastic (linear) or viscoelastic solution is considered. The cure was done within $4 \mathrm{~h}$ in a vacuum oven at $177^{\circ} \mathrm{C}$. The temperature required to make the panel flat was assumed as the stress-free temperature. The same approach for determination of stress-free temperature is used by Crasto and Kim in 1993 [33]. 


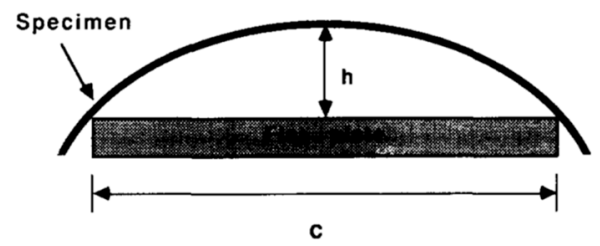

Figure 1. Curvature in cylindrical composite strip due to non-symmetric layup [32].

In a proceeding work in 1990 by White and Hahn [34], mechanical property changes and development of residual stresses during cure were investigated. Furthermore, they considered only the cool-down part and the strains due to chemical shrinkage were small and negligible, regarding their specific processing conditions.

Bogetti and Gillepsie simulated the curing process of thick-section composites for the distribution of temperature and degree of cure as a function of the autoclave temperature history. They performed this analysis with two-dimensional modelling in 1991 [35] and with a one-dimensional model in 1992 [15]. They compared their results with a similar approach from Kim and Hahn, 1989 [32]. They investigated the effect of different cure parameters. Cure shrinkage, resin modulus, and composite mechanical properties are assumed as cure dependent. Influence of various factors including thickness, resin modulus development, cure cycle, cure shrinkage, non-symmetric curing (about the mid-plane of the laminate), stacking sequence, amount of the stress-free temperature, and the influence of resin shrinkage on the assumed stress-free temperature were all investigated in their detailed study. As a consequence, since they predicted the evolution of stress throughout the complete curing process, there was no need to assume a stress-free temperature. The results demonstrated the significant influence that the resin shrinkage can have on the assumed stress-free temperature, and thus the magnitude of the resulting residual stress distributions.

White and Hahn, in 1992 [12], modelled the complete cure process with the linear viscoelastic formulation and concluded that the temperature dependence of the material properties should be considered and chemical shrinkage has a small contribution to the residual stresses if the relaxation time in the second phase of the cure is long enough. Note that the chemical shrinkage produces some amount of residual stress but on the other hand, the relaxation behaviour of the polymer, especially during the cool-down phase, relaxes the already developed residual stress by thermal deformations and chemical shrinkage and, therefore, the two mechanisms are counter-balancing if their order of magnitude is the same. In their cure cycle, the contribution of chemical shrinkage was lower than $4 \%$ in volume, but they declare that this part is not always negligible. If a fast cool-down occurs during or shortly after the chemical shrinkage, a considerable part of residual stress due to chemical shrinkage cannot be relaxed and would remain in the matrix. As a result, they state that a residual stress process model should incorporate viscoelastic material response, chemical and thermal shrinkage effects, and mechanical property development during the cure cycle. They investigated the mathematical modelling with experiments in the same year [12]. The measured thermal and chemical strains by strain gauges serving as inputs to the viscoelastic model.

Among the papers that consider the viscoelastic modelling of the curing of composites, Kim and White in 1997 [36] made a two-dimensional heat transfer model to calculate the temperature distribution over the thickness of the thick laminates. A cure-dependent viscoelastic material model was used for the prediction of residual stresses using a two-dimensional finite element model. The same authors in 1998 [37] presented the viscoelastic model for an orthotropic composite material and estimated the major viscoelastic stiffness components from experiments to predict the residual stresses in a graphite/epoxy composite.

In the research done by Theriault and Osswald in 1999 [38], chemical shrinkage is not considered. They stated that the stress built up in the cure of the matrix is relaxed when cooled from $\mathrm{T}_{\text {cure }}$ to $\mathrm{T}_{\mathrm{g}}$ and the residual stresses should be considered from $T_{g}$ and during the cool-down process. In this respect, Madhukar et al. in their papers in 2000 [39-41], have noted that in different resins, the contribution of 
matrix volume change in the residual stress is different and therefore chemical shrinkage contribution may be large and may not be negligible. By modelling the cure cycle, they present that changing the cycle may change the resulting residual stresses. Reduction of chemical (cross-linking) shrinkage stresses is done by a combination of stress relaxation and thermal expansion and completing the cure cycle in a short time.

As can be expected, process-induced residual stresses in a laminate have a considerable influence on the sensitivity to damage loads during the life-time performance. There exists some work done to minimise the amount of residual stresses by varying parameters of the cure cycle. In 1993, after simulation of the curing process, White and Hahn [42] investigated the control and reduction of process-induced residual stresses by modifying processing conditions for a graphite/BMI composite material. Residual stresses are decreased by changing parameters including cure time, dwell time, dwell temperature, cool-down rate, and pressure. Likewise, Olivier and Cottu in 1998 [43] optimised the cure cycle to minimise residual curing stresses while the mechanical characteristics remained constant. A similar thing was carried out by Madhukar et al. in 2000 [39-41], to reduce the residual stress in fibres.

Park and Lee, in 2001 [44], used finite element analysis to model the entire cure process and compared this to the experimental results available in the literature. The procedure is useful for computing the residual stresses during cure. Again modelling the entire cure process, Zhu et al. in 2001 [45] used a finite element method to solve the three-dimensional thermo-chemo-viscoelastic formulation, considering the heat transfer in the laminate to find the distribution of temperature. Through this effort, they state that a major part of the residual stress develops before cool-down. Since they have simulated the dimensional change of L-shaped graphite-epoxy profiles and using this formulation, they measured the larger spring-in and compared it with the case that only the cool-down stage is modelled using either elastic or viscoelastic modelling. It is important to note that in the case of thick composites, the temperature profile through the thickness is important to consider, which indeed makes the degree of cure non-uniform through the thickness. Likewise, Johnston et al., in 2001 [46], modelled the complete cure cycle. All the sources like heat transfer, cure kinetics (thermal expansion and cure-shrinkage), tool-part interfaces, and post-processing tool removal were included in their modelling. The model is applied to calculate the distortion of some L-shaped parts and had good accuracy for the prediction of both the spring-in angle and the warped shape of the composite part.

Oota and Saka, in 2001 [47], measured both cure and thermal shrinkages and presented a special method for measurement of the cure shrinkage. They verified that both sources contribute to the warpage.

In 2004, Svanberg and Holmberg [48,49] investigated the curing process by a viscoelastic model with strain, degree of cure, and temperature as the state variables. The variables were path-dependent instead of rate-dependent in the conventional viscoelasticity. Thermal and chemical parts were included and used in an ABAQUS subroutine. They also validated their model with some experimental measurements of the spring-in of some manufactured samples.

Shokrieh and Kamali, in 2005 [50], also considered only the cool-down stage of cure process and calculated the stresses and the curvature of non-symmetric composite laminates. They assumed that cooling starts from a stress-free temperature and compared the results with the measurements using the hole-drilling method. It was observed that the calculated residual stresses are greater than the ones measured by the experiments.

There is a review paper on the development of residual stresses in thermoplastic composites (Parlevliet et al. in 2006 and 2007 [51-53]). They investigated the effective factors in three levels of the material, consisting of micromechanical (constituents) level, macro mechanical level (ply to ply) due to lamina anisotropy, and global level (annealing and tool-part interaction). 
If the composite laminate is thick, the temperature distribution through the thickness of the laminate is important to be considered during the curing process. As an example, Guo et al. in 2005 [54] developed a one-dimensional thermo-chemical finite element model, which calculated the temperature profile due to the thermal heat source during chemical curing of the matrix.

In 2010, Abou-Msallem et al. evaluated the development of cure residual stresses of an epoxy matrix composite, considering the cure-dependent chemical shrinkage [55]. Furthermore, the peel-ply method was utilised to measure the residual stresses. In the same year, they solved the thermal, chemical, and mechanical equations for the cure cycle using a finite element code and by experimental verification [18]. They concluded that the stresses after gelation and before cool-down are considerable.

Ding et al., in 2015 [56], presented a three-dimensional finite element model for the prediction of residual stresses in composites implementing a user-defined material model in ABAQUS. In the year after, 2016, the same authors [57] investigated different constitutive models to predict the process-induced residual stresses in composites. Recently, researchers in 2016, 2018, and 2019 [58-60], compared elastic and viscoelastic numerical models for the curing-induced stresses in composites. Up to this point, the models for full composites, having thermoset resins, are mature and delicately developed. The models are accurate enough in the sense that validations have become possible through experimental measurement of residual stresses in composites. Later, this paper discusses the improvements in the same approaches for hybrid (fibre-metal) laminates.

\section{Predictive Models for Parameters during the Curing Process of Thermoset Polymers}

In this part, we will discuss first the papers that present some models useful for some parts of the cure cycle of thermoset polymers and composites. Afterward, the models used in the research done on the whole cure cycles will be reviewed.

\subsection{Modelling of Cure Kinetics}

The cure kinetics describe the amount of reaction as a function of time and temperature. Differential scanning calorimetry (DSC), as a conventional method, measures the heat flow into and from a sample. The onset and completion of cure, degree of cure (DOC), can be obtained from DSC. The internal heat, $\mathrm{H}$, generated per unit mass and per unit of time during the cross-link reaction and is represented as:

$$
\frac{d H}{d t}=H_{t o t} \frac{d \alpha}{d t}
$$

$H_{\text {tot }}$ is the total heat of the reaction after complete cure. Total heat of reaction and the cure rate can be determined using iso-conversion DSC measurements in which the sample is heated with a constant heat rate and the heat energy input to the sample is measured versus the cure time.

In order to calculate the degree of cure for any temperature history, DSC measurements are performed with different heating rates (for example 5, 6, 10, and $15{ }^{\circ} \mathrm{C} / \mathrm{min}$ ). Cure rates are measured and fitted to the Kamal-Sourour reaction rate equation [61]:

$$
\frac{d \alpha}{d t}=k_{0} e^{\left(\frac{-E_{A}}{R T}\right)} \alpha^{m}(1-\alpha)^{n}
$$

$R$ is the universal gas constant and $T$ is the temperature in Kelvin. $E_{A}$ is the activation energy and $k_{0}, m$, and $n$ are parameters. Figure 2 illustrates a typical cure measurement for an epoxy of the class FM-94, in which the cure development can be seen within the cure-cycle temperature history. 


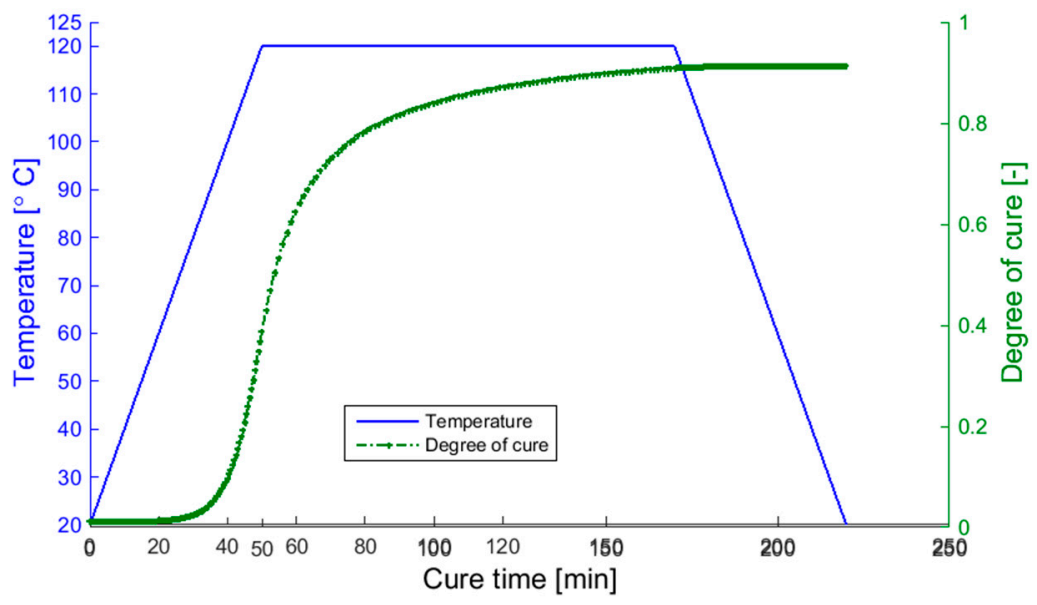

Figure 2. Cure cycle of CYTEC FM-64 epoxy [62].

Another cure kinetics model, for some class of polymeric materials as used by Bogetti and Gillespie in 1992 [15] for graphite/epoxy composites, is defined in Equation (3):

$$
\begin{array}{cl}
\frac{d \alpha}{d t}=\left(k_{1}+k_{2} \alpha\right)(1-\alpha)(0.47-\alpha) & \text { for } \quad(\alpha \leq 0.3) \\
\frac{d \alpha}{d t}=k_{3}(1-\alpha) & \text { for } \quad(\alpha>0.3)
\end{array}
$$

The Arrhenius rate expressions $k_{1}, k_{2}$, and $k_{3}$ are defined for the cure kinetics model as:

$$
\begin{aligned}
& k_{1}=A_{1} e^{\left(\frac{-\Delta E_{1}}{R T}\right)} \\
& k_{2}=A_{2} e^{\left(\frac{-\Delta E_{2}}{R T}\right)} \\
& k_{3}=A_{3} e^{\left(\frac{-\Delta E_{3}}{R T}\right)} .
\end{aligned}
$$

The above-mentioned models consider the cure kinetics of the thermoset polymers in the closed-mould processing, while there are some issues for open-mould composites. As in closed-mould processing, the polymer is heated up quickly to a holding temperature above the fully cured glass transition temperature $\left(\mathrm{T}_{\mathrm{g}}\right)$ and an external heat source, for example, the autoclave heater, is used for the curing evolution. However, in open-moulded processing, the exotherm of the polymerisation reaction provides the thermal input, and the curing process would be non-isothermal and dependent on the thermal diffusion since curing is achieved in low temperatures of only $10-20{ }^{\circ} \mathrm{C}$ above the ambient temperature. Capehart et al., in 2007 [63], introduced the cure model for thermoset composites within an open-mould processing cycle. They used an autocatalytic reaction equation, similar to Equation (2), for the cure kinetics accompanied with solving for the governing thermal-diffusion equation. As an example of experimental work in this aspect, cure kinetics of the epoxy resin was successfully modelled in 2010 by Ersoy and Tugutlu [64]. They proposed a method that measures the through-the-thickness cure shrinkage strains during curing of the composite in conventional DMA equipment.

\subsection{Resin Shrinkage during Cure}

Thermoset resins shrink during polymerisation. Each time a monomer reacts and bonds to the network, it is restricted in its movements and loses a certain amount of free volume. For all monomer molecules, this amount of loss of free volume is likely to be identical. Therefore, the loss of free volume (volumetric shrinkage) must be proportional to the degree of cure. The linear relation $\left(V_{c h}(q)=V_{c h}^{T} \cdot q\right)$ 
is used by many researchers $[15,37,65]$, where $V_{c h}^{T}$ is the total volumetric shrinkage of the thermoset polyme, which is, for example, about $3 \%$ for epoxies.

The linear shrinkage strain of the resin can be found as $\varepsilon_{c h}(q)=\sqrt[3]{1+V_{c h}(q)}-1 \cong \frac{1}{3} V_{c h}(q)$ for a small amount of $V_{c h}^{T}$. The equations can be further simplified by taking the linear shrinkage strain as:

$$
\varepsilon_{c h}(\alpha)=\varepsilon_{c, \max } \cdot \alpha .
$$

$\varepsilon_{c, \max }$ denotes the linear cure shrinkage after full conversion. As an example, the above model is used by the authors to model the stresses due to the curing cycle of the epoxy thermoset $[66,67]$.

For other works done on cure shrinkage of thermoset polymers, one can refer to the one done by Russel et al. in 1993 [68] and by Oota et al. in 2001 [47]. The curing shrinkage is of importance in the resins used in thermoset-based composite materials. Therefore, other researchers like Kaspar et al. in 2011 [69], Nawab et al. in 2012 [70], and Sadeghinia et al. in 2012 [71] have investigated the measurement of chemical shrinkage in thermoset composites, which affect the amount of residual stresses produced in these structural parts after curing. In 2012, Mergheim et al. [72] modelled the curing shrinkage of a thermoset polymer together with the resulting damage in the material due to the volumetric shrinkage and the produced stresses, which showed the importance of the consideration of the chemical shrinkage in the cure modelling of thermoset materials.

\subsection{Evolution of Resin Stiffness during Cure}

Thermo-mechanical characterisation of the resin material is needed since its mechanical properties change with the degree of cure and temperature. The properties, which vary due to polymerisation, include the elastic and viscous moduli. Some researchers have assumed a linear relationship between the stiffness and degree of cure [15] neglecting the glass transition temperature, viscoelastic relaxation, and temperature dependency. All the latter effects have been taken into account in some other works $[55,73,74]$.

The need for full characterisation of viscoelasticity depends on the thermoset system and cure cycle parameters. If the thermoset used is cured above its glass-transition temperature, dominant effects are from cure shrinkage and modulus increase during cure. Thermoset systems are usually cured above the glass transition temperature since systems that cure at a temperature below their glass transition will vitrify during curing, such that full conversion is never reached [75]. The reader is referred to other references describing the monitoring of the fibre reinforced polymer composites [76] and possible improvement in the curing process of thermoset materials [77-79].

Above glass-transition temperature, the material will be rubbery, and its stiffness depends only on cure polymerisation with negligible viscoelastic effects (stress relaxation) [80]. Therefore, if the resin is cured isothermally above $T_{g}$, the elastic modulus during cure can be approximated by its equilibrium modulus, which simplifies the cure modelling. The equilibrium modulus of the resin can then be modelled using percolation theory [80,81]. A simplified version of the theory is applied to the equilibrium shear modulus of the resin during cure in the Martin and Adolf model [82,83]:

$$
G_{R}(q)=G_{R}^{f}\left(\frac{\alpha q^{2}-q_{g e l}^{2}}{1-q_{g e l}^{2}}\right)^{\frac{8}{3}} \text { for } q>q_{g e l}
$$

$G_{R} f$ is the rubbery shear modulus in the final cured state, $q$ is the degree of cure, and $q_{g e l}$ is the gelation degree of cure. Some researchers have developed methods to measure the gelation point for thermoset polymers and prepreg materials that can be referred to for further reading [84-91]. Abouhamzeh et al. $[66,67]$ used the above formulation, Equation (5), to predict the curing response of the epoxy adhesive used in their hybrid material. For the cooling part of the cure cycle, they used a thermo-viscoelastic formulation in which the stiffness components of the composite material were 
viscoelastic (time-temperature dependent) during the cooling phase but no stress relaxation was considered during the curing part $[67,92,93]$.

Another model that takes into account the cure-dependency of the stiffness (modulus) of the thermoset polymer, is a so-called $\alpha$-mixing rule model [15]:

$$
\begin{gathered}
E_{m}(q)=\left(1-q_{\text {mod }}\right) E_{m}^{0}+q_{\text {mod }} E_{m}^{\infty}+\gamma q_{\text {mod }}\left(1-q_{\text {mod }}\right)\left(E_{m}^{\infty}-E_{m}^{0}\right) \\
\alpha_{\text {mod }}=\frac{q-q_{g e l}^{\text {mod }}}{q_{\text {diff }}^{\text {mod }}-q_{\text {gel }}^{\text {mod }}} \quad(-1<\gamma<1) .
\end{gathered}
$$

The parameters $E_{m}^{0}$ and $E_{m}^{\infty}$ are the fully uncured and fully cured temperature dependent resin moduli, respectively. The terms $q_{\text {gel }}^{\text {mod }}$ and $q_{\text {diff }}^{\text {mod }}$ represent the bounds on the degree of cure between which resin modulus is assumed to develop. The term $\gamma$ is introduced to quantify the competing mechanisms between stress relaxation and chemical hardening.

More accurate, and indeed more elaborate, models account for the cure-dependency of the material properties of the polymer (or composite), together with the stress relaxation occurring during cure. Note that providing such models not only requires detailed numerical modelling, but also more extensive experimental measurements and characterisations. Jansen et al. in $2004[94,95])$ and Van 'T Hof et al. in 2004 [96] investigated the relaxation (viscoelastic) response of thermosets during cure. Despite the applicability of linear viscoelasticity for most of the thermoset-type polymers, Adolf and Chambers (in 2007 [83]) used a nonlinear viscoelastic formulation for the cure-dependent viscoelastic modelling of epoxy-type thermosets.

Cure-dependence of the relaxation modulus of an epoxy adhesive is measured by $\mathrm{O}^{\prime} \mathrm{Berien}$ et al. in 2001 [97]. The measurements were carried out by parallel plate rheology equipment and the relaxation shear modulus of the epoxy was determined, which was dependent on time and the degree of cure. Such a material model can be useful for cure processes in which the polymer shows relaxation during the curing phase of the manufacturing cycle. As an example, for curing a thermoset composite at a temperature much below the glass transition, Capehart et al. in 2007 [63] used a Prony series for the viscoelastic shear modulus during the cure as in Equation (7):

$$
G(t)=G_{0}\left(1-\sum_{i=1}^{n}\left(1-e^{\frac{-t}{\tau_{i}^{0}}}\right)\right)
$$

The equilibrium (relaxed) shear modulus of the epoxy, during cure, was assumed to be cure-dependent as in Equation (5). Similar modelling is presented by Vreugd et al. in 2010 [80] but formulating a logarithmic form of the Havriliak-Negami function of the frequency $\omega$ :

$$
\log G(\alpha, T, \omega)=\log G_{r}(\alpha)+\frac{\log G_{g}-\log G_{r}(\alpha)}{\left(1+\left(\frac{w \tau_{0}}{a_{T, \alpha}}\right)^{-m}\right)^{n}}
$$

where $m$ and $n$ are the fitting parameters, $G_{g}$ and $G_{r}$ the glassy and rubbery shear modulus, respectively. The shift factor $a_{T, \alpha}$ counts for the dependency on temperature and the degree of cure (conversion). Again, the rubbery shear modulus $G_{r}$ is defined dependent on the degree of cure, as in Equation (5).

There are also other works dealing with the cure-dependent viscoelastic response of thermosetting polymers, as by Kim and White in 1996 [98] for 3501-6 epoxy resin. However, in their paper, Kim and White considered a cure-dependent shift function for a thermo-rheologically complex system that needs a vertical shifting as well as a horizontal one in the time axis to define the master curve for the relaxation modulus. 


\section{Stress Models for Thermoset Polymers and Adhesives}

Pure polymers, without reinforcing fibres, have applications in the bonding of parts and sheets as an adhesive and as coatings in electronic packages. Whilst the models needed further development for composites, elaborate predictive models exist already for isotropic thermoset polymers that we hereby refer to some of them, as follows:

In 1995, Wang et al. [99] measured residual stresses, including a curing shrinkage stress and cooling shrinkage stress, automatically and continuously during curing and cooling. For the measurements, they coated the epoxy resin on some aluminium strips. One important note we can extract from their work is that if the cure temperature is low and the test time is shorter than the apparent gelation time, no residual stress will remain in the resin. They state that in the first stages of cure, from ambient temperature to cure temperature and until the middle of the cure stage, the degree of cure in the epoxy resin is low and therefore the residual stresses due to the cure shrinkage do not remain and will be relaxed. However, after gelation, the stresses get locked (due to the low rate of stress relaxation) and the gelation point is the start of residual stress build-up. From $t_{g e l}$ up to the start of cool-down, some cure shrinkage stresses will be created, which are much smaller than the residual stresses due to cooling. The ratio to the total residual stresses is about $5 \%$. In their work, a finite strip is used, and the stresses are calculated from Timoshenko beam theory based on a linear elastic behaviour.

In 1996, Adolf and Martin [82] calculated the residual stresses in cross-linking (epoxy) polymers during the curing process, considering the viscoelastic relaxation of the polymer. Stress build-up process for thermosets is also dependent on the cure temperature. In 1997, Lang et al. [100,101] studied the residual stress development in thermoset resins in two cases: Cure below and above the resin's glass transition temperature $\left(\mathrm{T}_{\mathrm{g}}\right)$. They first investigated the curing process below $\mathrm{T}_{\mathrm{g}}$. They concluded that in general, the stress build-up depended on the crosslink density. Stress induced in the curing phase ranged from less than $1 \%$ of the total residual stress (for cure and cool-down) in a lightly cross-linked epoxy to more than $30 \%$ of the total residual stress in densely cross-linked epoxies and acrylates. Therefore, they conclude that the contribution of the isothermal curing part is generally important to take into account. When the cure temperature is above the $T_{g}$, the epoxy, as available from the literature, exhibited no detectable stress during the curing reaction, nor during cooling down to the glass transition temperature but develops residual stress below $\mathrm{T}_{\mathrm{g}}$. However, the acrylate generated considerable residual stress with the major part above $\mathrm{T}_{\mathrm{g}}$, throughout the reaction and cooling.

Many researchers have done simulation of the cure cycle of thermoset polymers. For example, Zhang et al. simulated the cure cycle for epoxy resins to evaluate the effect of different cure-cycle parameters on the final properties of the resin, in 2009 and 2010 [102,103]. A more general material model was presented by Liebl et al. in 2012 [104] for curing thermoset adhesives accounting for viscoelastic-viscoplastic responses. Temperature and degree of cure were the problem variables that they evaluated for their effect on the mechanical properties of the adhesive. They considered thermal and chemical shrinkage within material modelling.

One practical example of the usefulness of cure-induced stress models for thermoset polymers is in the application of thermoset polymers in the electronic packaging industry in which the resulting distortions are undesirable in the product. Various publications exist from a group of researchers at the Delft University of Technology who have measured the cure-dependent and viscoelastic response of the packaging (thermoset) polymers. Based on the characterisations, they developed models to predict the warpage and residual stresses. For the details of such modelling and experimental achievements, the reader is recommended to have a look at their published papers $[69,74,80,95,96,105-113]$. For example, Jansen et al., in 2012 and 2013, developed an analytic model based on classical laminate theory (CLT) for single and multi-layered coating layers used in electronic packaging and predicted the resulting warpage due to the curing process $[75,114]$. The approach was later improved by the authors in 2016 to make the model applicable for the CLT analysis of the cure-induced deformations of thin composite materials [66]. The model included the thermal deformations and cure shrinkage of the epoxy thermoset, but the viscoelastic response of the epoxy material was not accounted for. 
An improved analytic solution was provided by Liu and Shi in 2018 [115] to predict the residual stresses and deformations, which considered the thermo-viscoelastic effects.

\section{Predicting and Reducing the Distortions in Thermoset Composites}

Possible deviations, from the designed shape of the composite part, are called distortions. Distortions can be of several types: spring-in, spring-back, and warpage. Spring-in and spring-back occur in curved composite laminates as a change in the enclosed angle of the part due to elastic responses of the laminate. When the enclosed angle decreases, it is called spring-in and when it is increased, it is called spring-back. The distortion that occurs even in flat and balanced laminates is named warpage that is normally caused by the tool-part interaction.

According to the above descriptions on the mechanisms governing the distortion of composites, different research groups have worked on these topics, from which an overall review shows the trends and improvements in this area.

In 1996, L. Peeters et al. [116] revised some models that were previously developed to predict the shape of laminates after manufacturing. In their paper, they performed some extended experimental studies on cross-ply and angle-ply laminates on a flat mould.

It is desirable to have a mathematical model to predict the distortions of the structure parametrically. However, solving the equations governing the manufacturing processes is not possible analytically. Therefore, investigating the problem or solving the equations using the finite element method would be the best choice. In 2001, Oota and Saka [47] measured the total shrinkage of the epoxy matrix of a laminate used in an electronic device and included the shrinkage in their finite element analysis. Later in 2002, Albert and Fernlund investigated the spring-in and warpage in angled parts made from laminated composites [117].

In 2002, G. Fernlund et al. [25] carried out some experiments to study the factors influencing the dimensional changes of laminated structures. They stated that different factors other than thermal expansion and resin cure shrinkage are important, like cure cycle, tool surface (interaction), part geometry, and of course, the lay-up.

Considering the influence of cooling rate, Sun and Pang, in 2002 [118], compared the curvatures of non-symmetric laminates made from AS4-carbon/8552-epoxy, when quenched (cooled quickly) and again cooled slowly, and they did not see much difference. As a result, the cooling rate did not have any effect on the final spring-in angles.

In 2002, Nawab et al. [17] developed a finite element model to account for different contributions in the spring-in of a thermoset laminate. They included shrinkage, volume fraction gradient, and tool-part interaction in their model, which was up to $80 \%$ accurate. A similar approach was chosen by Darrow and Smith in 2002 [20] and Bapanapalli and Smith in 2005 [119], accounting for thickness shrinkage, mould stretching (tool-part interaction), and fibre volume fraction gradient in the material. They concluded, from experimental investigations and linear solutions with the finite element model, that the thickness shrinkage was the main parameter that contributed approximately $75 \%$ of the measured distortion. For measurement of the spring-in, they have processed digital images from the test samples.

Traditionally, the expected shape deviation in manufacturing composite laminates can be compensated for in the tool design using experience such that the warped part has the desired dimensions and shape. The procedure is known as tool compensation. Despite the simplicity of the concept, the process is unique for each part with its features like layup, etc., resulting in a costly and time-consuming effort to do this for each laminate type. Therefore, research has been performed to compensate for the distortion that occurred during manufacturing composite laminates. As an example, one can refer to the work done by Jung et al. in 2006 [120], in which spring-back of two types of open laminated shells were estimated with experiment and finite element analysis. Using finite element analysis, the deviation angle of the mould was changed in each run of ANSYS, and the difference between the calculated and real product angles becomes zero with different modelling parameters. 
In 2007, Capehart et al. [121] developed a finite element model by utilising a simpler elastic constitutive relation for the equilibrium mechanical response of the laminate layers. Semi-quantitative models were used for estimating the lateral stress produced by chemical shrinkage during thermoset cure. The finite element analysis is evaluated by the test but $20 \%$ deviation (error) existed. The corrected moulds are designed and adjusted for manufacturing distortions in a trial and error process to converge to an optimal solution. The procedure for the corrective mould yielded $45 \%$ reduction in the final distortions. In the same year (2007), Jung et al. [122] measured the spring back in a composite beam using experimental measurements, modelling with classical laminate theory (CLT) and finite element analysis using the ANSYS software package. For compensation, CLT modelling predictions are used, and the web-based strategy incorporates the online modifications in the machining code for machining of the updated mould.

Spring-in of a thermoset composite with C-shape was investigated in 2010 by Ersoy et al. [123] using a finite element model. Similar experiments are performed, as explained by the same authors in [124], to measure the angles in curved laminates. In 2011, K. Magniez et al. [125] measured the shrinkage during curing using density measurements and it was less than $3 \%$, so the main part of the shrinkage was due to the cool-down process.

As an example of a more complicated analysis of the autoclave cure process, Abdelal et al. simulated the chemical cure process together with the contact between the composite and the mould (tool) in 2013 [126]. They used an explicit finite element solver to overcome the numerical problems arising from the nonlinear contact analysis and included the thermal and mechanical properties of the contact layer, which may be modified to decrease the final deformations. Another similar work was done by Tavakol et al. in 2013 providing a coupled thermo-mechanical finite element model for the curing and tool-part interaction of an IM7/977-2 prepreg made of IM7 fibres and CYTEC CYCOM 977-2 toughened epoxy resin [127].

\section{Manufacturing-Induced Residual Stresses and Distortions in Fibre Metal Laminates (FML)}

\subsection{Introduction}

Hybrid materials are composed of composite and metal parts. Besides their high values of strength/weight ratios, alternating metal and composite layers in FML allow them to obtain high structural performances like fatigue life, residual strength, and damage tolerance (Figure 3). Glass aluminiumreinforced epoxy (GLARE) serves as the most common type, which is used in fuselage panels and leading edges of tail planes of Airbus A-380.

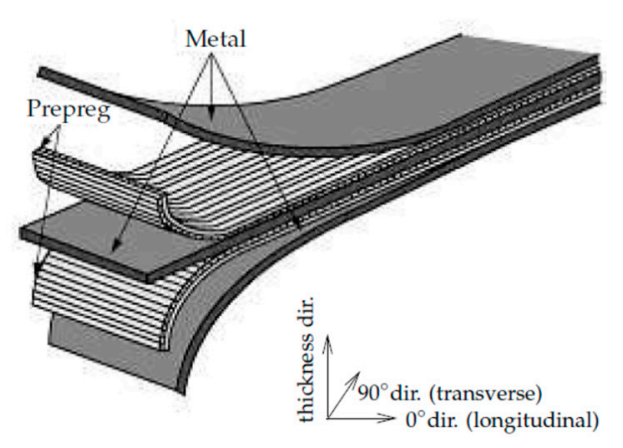

Figure 3. Typical configuration of glass aluminium-reinforced epoxy (GLARE) [128].

Integrated GLARE panels are made by curing of prepreg layers (with glass fibres and epoxy adhesive) between aluminium sheets. Reinforcements like doublers and stringers are attached to the already cured laminates using a second cure cycle. The epoxy adhesive in the prepreg layers of FML behaves in a temperature-dependent and viscoelastic manner in thermal environments. As a result, GLARE shows stress relaxation in the cure cycles during the manufacturing of the integrated fuselage 
panel. However, despite the extended research on the material improvements [129-133], only a few works have been done recently on the cure-induced residual stresses of FML/GLARE.

Different types of distortions may be present after manufacturing an FML skin panel. There are two manufacturing stages in which residual stresses are created: First layup-cure and second post-cure processes.

Since FML have metal layers, the metal sheet forming processes should be considered as they react in the same way as in the cold forming of FML. It should be noted that these forming techniques induce both elastic and plastic deformations. The product springs back due to the elastic recovery when the loads are removed. Actually, the elastic energy restored in the material partly releases as spring-back and partly remains in the material as residual stress. In the curing of simple curved shells from FML, no plastic strain is encountered. However, in forming FML stringers as reinforcement of skins, bending is required that takes the aluminium layers of FML into the plastic region. The shape deviation may be large, and compensation may then be necessary. The conventional processes in the manufacturing of metallic shapes include bending, stretching, and deep drawing.

Research has already been performed to produce metallic parts with less shape deviations, some of which are presented here to exemplify the used concepts.

When the metallic part is bent, the part angle increases and deviates from the bending angle during the process. Without predicting the distortions, corrections are made usually based on experiments that take a long time and are costly as well. The shape after bending and spring-back of the sheet metal is taken into consideration in the bending die design [134]. As a result, the spring-back angles of different sheet metals with different bending angles were obtained. The tool geometry is optimised in [135] to compensate spring-back within the deep drawing process using finite element analyses. For more detail on the calculation and compensation of spring-back in metal-forming processes, one can refer to other research results available [134-139].

Spring-back can occur within the layup process of FML, due to forming of the metal part. Kim et al., in 2007 [140], considered the brake-forming process for producing GLARE stringers; they used a 3D laser scan to measure the spring-back. They studied the effect of design and process parameters on the value of the spring-back angle, including punch radius, punch speed, forming load, and forming temperature. Krimbalis et al. in 2008 [141] calculated the residual stresses in rectangular symmetric FML using simple force-equilibrium equations. In 2003, Hofslagare [142] measured the residual stress in the aluminium layer of an FML with three methods: X-ray diffraction, neutron diffraction, and strain measurement during stress release induced by delamination, which showed good agreement with each other. It can be concluded that some primary investigations have been carried out on the distortions of FML with no deep insight into the mechanisms and components affecting the geometry and stress state of the hybrid material as it has been contrarily performed on full composites.

\subsection{Effective Parameters in the Manufacturing of FML}

In the cure cycle of FML, distortions are actually due to the mechanisms already described in detail for full composites where both chemical shrinkage of the resin and the thermal shrinkage due to different properties of the constituents play a role. Different properties between the prepreg layers and metal layers are the principal sources. Of course, forming processes will also make distortions and spring back, which are not desired. For instance, the distortions due to metal forming of stringers need further investigation.

According to the review made on full composites and FML, effective parameters in different development mechanisms of residual stresses and distortions in FML, consist of the following:

- $\quad$ Stacking Sequence (laminate layup);

o The difference in CTE of constituents in different directions;

o Difference in shrinkage of the prepreg in different directions during cure;

- Cure Cycle parameters like temperature, pressure, heating/cooling rates (see Figure 2); 
- Material properties of the ingredients (resin type, fibre material, metal type);

- The thickness of layers in the laminate;

- Tool parameters like material properties and the friction between the tool and the laminate;

- Mould effect, which can be described as the boundary conditions that are imposed to the laminate while having deformations in different layers during the cure cycle;

After curing of FML, due to special applications and designs, some other processes may change the stress distribution of the laminate (see Figure 4), which can be listed as follows:

- Trimming and drilling;

- Creating cut-outs for doors and windows of the fuselage panel;

- Attachment of reinforcement, i.e., large doublers and stringers in a second (bonding) cure cycle;
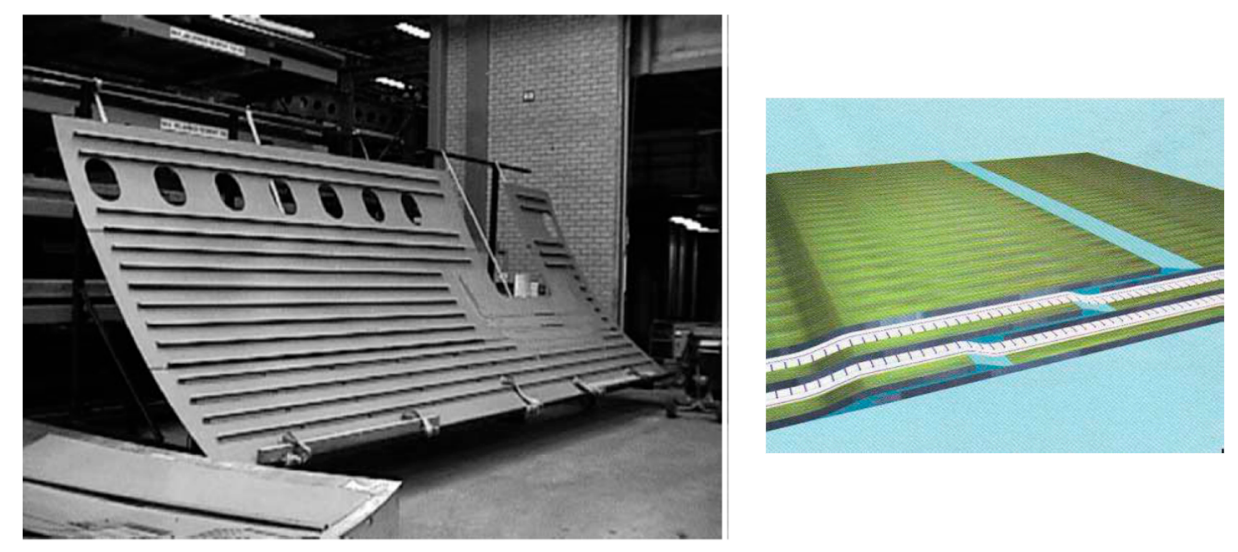

Figure 4. A fuselage panel made from fibre metal laminates (FMLs). Left: cut-outs, doublers, and stringers; right: overlap splice between adjacent panels.

A tool-compensation procedure can be followed for FML to design a revised mould to manufacture accurate skin panels from FML.

\subsection{Research on the Prediction of Residual Stresses in FML}

Since metals have a significant contribution to the design-manufacturing of FML, less attention has been paid to the composite part in the production of residual stresses. In the development phase of FML, in the modelling approaches, researchers have only considered the cool-down part of the cure cycle. In other words, effects from curing of the composite layers, which cause chemical shrinkage, and the effect from the stiffness evolution of the adhesive were neglected. As an application example, to study the fatigue response of FML, residual stresses play an important role in the initiation and growth of the cracks. See, for instance [131], in which the residual stresses were traditionally estimated by taking the $\mathrm{T}_{\text {cure }}$ as the starting point to calculate the thermal stresses developed during cooling. In other relevant works on fibre metal laminates (FML), a similar approach is chosen to account for the residual stresses $[143,144]$. Here, the research currently available for FML is described concisely.

Research is being conducted at TU Delft, Faculty of Aerospace Engineering on the analysis and prediction of manufacturing processes on a fuselage panel made of GLARE. Preliminary modelling and experiments are already being carried out to study the contribution of different mechanisms on the initiation of residual stress and distortion of GLARE samples $[145,146]$. The research methodology was also presented at ECCM16 [147]. The shape deviations should be predictable prior to manufacturing, to be compensated in the tooling to achieve easy and accurate assembly. Knowing the residual stress values, or possibly decreasing them, helps to achieve better structural responses in the service life of the material [146]. The mould geometry can be adapted accordingly to produce (much) more accurate products and also minimise the residuals stresses of the panels. 
Integrated GLARE panels are made by curing of prepreg layers (with glass fibres and epoxy adhesive) between aluminium sheets. Reinforcements like doublers and stringers would also be attached to the already cured laminates using a second cure cycle. The epoxy adhesive in the prepreg layers of FMLs behaves in a temperature-dependent and viscoelastic manner in thermal environments. As a result, GLARE shows stress relaxation in the cure cycles during manufacturing the integrated fuselage panel. However, despite the extended research on the material improvements [129-133], the viscoelastic response of GLARE has not been considered yet. The cure, thermal, and viscoelastic properties of Epoxy FM-94, used in prepreg layers of GLARE, are already characterised by the authors in previous works. The material response was needed as the input to the model for predicting the residual stresses after cure cycles of GLARE panels. Consequently, the thermo-elastic and thermo-viscoelastic response of the adhesive in GLARE was determined using thermo-mechanical analysis (TMA) and dynamic-mechanical analysis (DMA) [62]. The viscoelastic response of the composite (prepreg) layers of the FML was obtained from the already determined temperature-dependent and viscoelastic response of the epoxy adhesive [93]. The correspondence principle is implemented together with self-consistent micromechanics equations in the Laplace domain, and then the time response is obtained by an inverse transform [92].

These materials may exhibit large deformations due to non-symmetry after the cooling part of the cure cycle. Therefore, a material modelling procedure was developed for large-displacement (but with small strains) analysis of a thermo-viscoelastic orthotropic material. The model was included in a finite element package for different types of geometries and elements [67].

\section{Conclusions}

In this paper, detailed modelling and experimental works were reviewed on the manufacturinginduced phenomena in thermoset type composites. First, the sources that produce the residual stresses and distortions in thermoset-based composites were described, and the available research papers were reviewed. Second, the modelling approaches for pure thermoset polymers and thermoset composites were presented. At the same time, the models needed for different parts of the processing cycle of the thermoset material were discussed, together with the characterisations needed to derive the physical parameters as the input to the models. Up to this point, what can be concluded is that all of the physical parameters present in the processing of these composite materials are modelled and characterised in the literature. However, newer generations of laminates like hybrid materials are also using thermoset polymers as matrix or adhesive. The last part of this paper gave an overview of the relevant works done on hybrid fibre metal laminates (FML). Characterisations and modelling procedures should be followed for these kinds of advanced materials. Some works are carried out by the authors at TU Delft, which need to be completed with more modelling verifications as well as measurements on the residual stresses, which have been addressed in this paper. FML had limited but successful usage in the fuselage panels of Airbus A380. However, the application is lifted, and the industry is searching for other alternatives.

Review of the works on thermoplastic composites was not in the scope of this review paper, but based on the authors' knowledge, less dedicated models exist for the processing of thermoplastic composites. This has particular importance since the aviation industry is investing more in the thermoplastic components than the past when the application was limited to secondary structural parts.

Author Contributions: M.A. has done the research and written the article. J.S. was the supervisor of the research and R.B. was the section head and promotor of the research.

Funding: This research received no external funding.

Conflicts of Interest: The authors declare no conflict of interest.

\section{References}

1. Hahn, H.T.; Pagano, N.J. Curing stresses in composite laminates. J. Compos. Mater. 1975, 9, 91-106. [CrossRef] 
2. Hahn, H.T. Residual stresses in polymer matrix composite laminates. J. Compos. Mater. 1976, 10, $266-278$. [CrossRef]

3. Kim, R.Y.; Hahn, H.T. Effect of curing stresses on the first ply-failure in composite laminates. J. Compos. Mater. 1979, 13, 2-16. [CrossRef]

4. Weitsman, Y. Residual thermal stresses due to cool-down of epoxy-resin composites. J. Appl. Mech. 1979, 46, 563-567. [CrossRef]

5. Hyer, M.W. Calculations of the room-temperature shapes of unsymmetric laminatestwo. J. Compos. Mater. 1981, 15, 296-310. [CrossRef]

6. Doi, O.; Kataoka, K. Residual stress measurement of laminated anisotropic plate by strain gauge method. Bull. JSME 1982, 25, 1373-1377. [CrossRef]

7. Hyer, M.W. The room-temperature shapes of four-layer unsymmetric cross-ply laminates. J. Compos. Mater. 1982, 16, 318-340. [CrossRef]

8. Jones, F.R.; Mulheron, M.; Bailey, J.E. Generation of thermal strains in GRP. J. Mater. Sci. 1983, 18, $1522-1532$. [CrossRef]

9. Nairn, J.A.; Zoller, P. Matrix solidification and the resulting residual thermal stresses in composites. J. Mater. Sci. 1985, 20, 355-367. [CrossRef]

10. Kataoka, K.; Dol, O.; SATO, M. Residual stress measurement of laminated anisotropic plate by strain gauge method in consideration of strain gauge stiffness and gauge base thickness. Bull. JSME 1986, 29, 393-399. [CrossRef]

11. Akira, H.; Hyer, M.W. Non-linear temperature-curvature relationships for unsymmetric graphite-epoxy laminates. Int. J. Solids Struct. 1987, 23, 919-935. [CrossRef]

12. White, S.R.; Hahn, H.T. Process modeling of composite materials: Residual stress development during cure. Part II. Experimental validation. J. Compos. Mater. 1992, 26, 2423-2453. [CrossRef]

13. Radford, D.W.; Rennick, T.S. Separating sources of manufacturing distortion in laminated composites. J. Reinf. Plast. Compos. 2000, 19, 621-641. [CrossRef]

14. Wisnom, M.R.; Gigliotti, M.; Ersoy, N.; Campbell, M.; Potter, K.D. Mechanisms generating residual stresses and distortion during manufacture of polymer-matrix composite structures. Compos. Part A Appl. Sci. Manuf. 2006, 37, 522-529. (In English) [CrossRef]

15. Bogetti, T.A.; Gillespie, J.W., Jr. Process-induced stress and deformation in thick-section thermoset composite laminates. J. Compos. Mater. 1992, 26, 626-660. [CrossRef]

16. Tai, H.J.; Chou, H.L. Chemical shrinkage and diffusion-controlled reaction of an epoxy molding compound. Eur. Polym. J. 2000, 36, 2213-2219. [CrossRef]

17. Nawab, Y.; Jacquemin, F.; Casari, P.; Boyard, N.; Sobotka, V. Shape evolution of carbon epoxy laminated composite during curing. In Key Engineering Materials; Trans Tech Publications: New York, NY, USA, 2012; Volume 504, pp. 1145-1150.

18. Msallem, Y.A.; Jacquemin, F.; Boyard, N.; Poitou, A.; Delaunay, D.; Chatel, S. Material characterization and residual stresses simulation during the manufacturing process of epoxy matrix composites. Compos. Part $A$ Appl. Sci. Manuf. 2010, 41, 108-115. [CrossRef]

19. Kelly, G.; Lyden, C.; Lawton, W.; Barrett, J.; Saboui, A.; Pape, H.; Peters, H.J. Importance of molding compound chemical shrinkage in the stress and warpage analysis of PQFPs. IEEE Trans. Compon. Packag. Manuf. Technol. Part B Adv. Packag. 1996, 19, 296-300. [CrossRef]

20. Darrow, D.A., Jr.; Smith, L.V. Isolating components of processing induced warpage in laminated composites. J. Compos. Mater. 2002, 36, 2407-2419. [CrossRef]

21. Wisnom, M.R.; Potter, K.D.; Ersoy, N. Shear-lag analysis of the effect of thickness on spring-in of curved composites. J. Compos. Mater. 2007, 41, 1311-1324. [CrossRef]

22. Ersoy, N.; Potter, K.; Wisnom, M.R.; Clegg, M.J. An experimental method to study the frictional processes during composites manufacturing. Compos. Part A Appl. Sci. Manuf. 2005, 36, 1536-1544. [CrossRef]

23. Kappel, E.; Stefaniak, D.; Spröwitz, T.; Hühne, C. A semi-analytical simulation strategy and its application to warpage of autoclave-processed CFRP parts. Compos. Part A Appl. Sci. Manuf. 2011, 42, 1985-1994. [CrossRef]

24. Cho, M.; Kim, M.H.; Choi, H.S.; Chung, C.H.; Ahn, K.J.; Eom, Y.S. A study on the room-temperature curvature shapes of unsymmetric laminates including slippage effects. J. Compos. Mater. 1998, 32, 460-482. [CrossRef] 
25. Fernlund, G.; Rahman, N.; Courdji, R.; Bresslauer, M.; Poursartip, A.; Willden, K.; Nelson, K. Experimental and numerical study of the effect of cure cycle, tool surface, geometry, and lay-up on the dimensional fidelity of autoclave-processed composite parts. Compos. Part A Appl. Sci. Manuf. 2002, 33, 341-351. [CrossRef]

26. Twigg, G.; Poursartip, A.; Fernlund, G. An experimental method for quantifying tool-part shear interaction during composites processing. Compos. Sci. Technol. 2003, 13, 1985-2002. [CrossRef]

27. Twigg, G.; Poursartip, A.; Fernlund, G. Tool-part interaction in composites processing. Part I: Experimental investigation and analytical model. Compos. Part A Appl. Sci. Manuf. 2004, 35, 121-133. [CrossRef]

28. Twigg, G.; Poursartip, A.; Fernlund, G. Tool-part interaction in composites processing. Part II: Numerical modelling. Compos. Part A Appl. Sci. Manuf. 2004, 35, 135-141. [CrossRef]

29. Kaushik, V.; Raghavan, J. Experimental study of tool-part interaction during autoclave processing of thermoset polymer composite structures. Compos. Part A Appl. Sci. Manuf. 2010, 41, 1210-1218. [CrossRef]

30. Zeng, X.; Raghavan, J. Role of tool-part interaction in process-induced warpage of autoclave-manufactured composite structures. Compos. Part A Appl. Sci. Manuf. 2010, 41, 1174-1183. [CrossRef]

31. Favre, J.P. Residual thermal stresses in fibre reinforced composite materials-A review. J. Mech. Behav. Mater. 1988, 1, 37-53.

32. Kim, K.S.; Hahn, H.T. Residual stress development during processing of graphite/epoxy composites. Compos. Sci. Technol. 1989, 36, 121-132. [CrossRef]

33. Crasto, A.S.; Kim, R.Y. On the determination of residual stresses in fiber-reinforced thermoset composites. J. Reinf. Plast. Compos. 1993, 12, 545-558. [CrossRef]

34. White, S.R.; Hahn, H.T. Mechanical property and residual stress development during cure of a graphite/BMI composite. Polym. Eng. Sci. 1990, 30, 1465-1473. [CrossRef]

35. Bogetti, T.A.; Gillespie, J.W., Jr. Two-dimensional cure simulation of thick thermosetting composites. J. Compos. Mater. 1991, 25, 239-273. [CrossRef]

36. Kim, Y.K.; White, S.R. Viscoelastic analysis of processing-induced residual stresses in thick composite laminates. Mech. Compos. Mater. Struct. 1997, 4, 361-387. [CrossRef]

37. White, S.R.; Kim, Y.K. Process-induced residual stress analysis of AS4/3501-6 composite material. Mech. Compos. Mater. Struct. 1998, 5, 153-186. [CrossRef]

38. Theriault, R.P.; Osswald, T.A.; Castro, J.M. Processing induced residual stress in asymmetric laminate panels. Polym. Compos. 1999, 20, 493-509. [CrossRef]

39. Genidy, M.S.; Madhukar, M.S.; Russell, J.D. A new method to reduce cure-induced stresses in thermoset polymer composites, Part II: Closed loop feedback control system. J. Compos. Mater. 2000, 34, 1905-1925. [CrossRef]

40. Madhukar, M.S.; Genidy, M.S.; Russell, J.D. A new method to reduce cure-induced stresses in thermoset polymer composites, part I: Test method. J. Compos. Mater. 2000, 34, 1882-1904. [CrossRef]

41. Russell, J.D.; Madhukar, M.S.; Genidy, M.S.; Lee, A.Y. A new method to reduce cure-induced stresses in thermoset polymer composites, part III: Correlating stress history to viscosity, degree of cure, and cure shrinkage. J. Compos. Mater. 2000, 34, 1926-1947. [CrossRef]

42. White, S.R.; Hahn, H.T. Cure cycle optimization for the reduction of processing-induced residual stresses in composite materials. J. Compos. Mater. 1993, 27, 1352-1378. [CrossRef]

43. Olivier, P.; Cottu, J.P. Optimisation of the co-curing of two different composites with the aim of minimising residual curing stress levels. Compos. Sci. Technol. 1998, 58, 645-651. [CrossRef]

44. Park, H.C.; Lee, S.W. Cure simulation of thick composite structures using the finite element method. J. Compos. Mater. 2001, 35, 188-201. [CrossRef]

45. Zhu, Q.; Geubelle, P.H.; Li, M.; Tucker, C.L., III. Dimensional accuracy of thermoset composites: Simulation of process-induced residual stresses. J. Compos. Mater. 2001, 35, 2171-2205. [CrossRef]

46. Johnston, A.; Vaziri, R.; Poursartip, A. A plane strain model for process-induced deformation of laminated composite structures. J. Compos. Mater. 2001, 35, 1435-1469. [CrossRef]

47. Oota, K.; Saka, M. Cure shrinkage analysis of epoxy molding compound. Polym. Eng. Sci. 2001, 41, $1373-1379$. [CrossRef]

48. Svanberg, J.M.; Holmberg, J.A. Prediction of shape distortions Part I. FE-implementation of a path dependent constitutive model. Compos. Part A Appl. Sci. Manuf. 2004, 35, 711-721. [CrossRef]

49. Svanberg, J.M.; Holmberg, J.A. Prediction of shape distortions. Part II. Experimental validation and analysis of boundary conditions. Compos. Part A Appl. Sci. Manuf. 2004, 35, 723-734. [CrossRef] 
50. Shokrieh, M.M.; Kamali, S.M. Theoretical and experimental studies on residual stresses in laminated polymer composites. J. Compos. Mater. 2005, 39, 2213-2225. [CrossRef]

51. Parlevliet, P.P.; Bersee, H.E.; Beukers, A. Residual stresses in thermoplastic composites-A study of the literature-Part I: Formation of residual stresses. Compos. Part A Appl. Sci. Manuf. 2006, 37, 1847-1857. [CrossRef]

52. Parlevliet, P.P.; Bersee, H.E.; Beukers, A. Residual stresses in thermoplastic composites-A study of the literature-Part II: Experimental techniques. Compos. Part A Appl. Sci. Manuf. 2007, 38, 651-665. [CrossRef]

53. Parlevliet, P.P.; Bersee, H.E.; Beukers, A. Residual stresses in thermoplastic composites-A study of the literature. Part III: Effects of thermal residual stresses. Compos. Part A Appl. Sci. Manuf. 2007, 38, 1581-1596. [CrossRef]

54. Guo, Z.S.; Du, S.; Zhang, B. Temperature field of thick thermoset composite laminates during cure process. Compos. Sci. Technol. 2005, 65, 517-523. [CrossRef]

55. Abou-Msallem, Y.; Kassem, H.; Jacquemin, F.; Poitou, A. Experimental study of the induced residual stresses during the manufacturing process of an aeronautic composite material. Res. J. Appl. Sci. Eng. Technol. 2010, 2, 596-602.

56. Ding, A.; Li, S.; Wang, J.; Zu, L. A three-dimensional thermo-viscoelastic analysis of process-induced residual stress in composite laminates. Compos. Struct. 2015, 129, 60-69. [CrossRef]

57. Ding, A.; Li, S.; Wang, J.; Zu, L. A comparison of process-induced residual stresses and distortions in composite structures with different constitutive laws. J. Reinf. Plast. Compos. 2016, 35, 807-823. [CrossRef]

58. Wang, X.; Zhao, Y.; Su, H.; Jia, Y. Curing process-induced internal stress and deformation of fiber reinforced resin matrix composites: Numerical comparison between elastic and viscoelastic models. Polym. Polym. Compos. 2016, 24, 155-160. [CrossRef]

59. Li, D.; Li, X.; Dai, J.; Xi, S. A comparison of curing process-induced residual stresses and cure shrinkage in micro-scale composite structures with different constitutive laws. Appl. Compos. Mater. 2018, 25, 67-84. [CrossRef]

60. Dai, J.; Xi, S.; Li, D. Numerical analysis of curing residual stress and deformation in thermosetting composite laminates with comparison between different constitutive models. Materials 2019, 12, 572. [CrossRef]

61. Sourour, S.; Kamal, M.R. Differential scanning calorimetry of epoxy cure: Isothermal cure kinetics. Thermochim. Acta 1976, 14, 41-59. [CrossRef]

62. Abouhamzeh, M.; Sinke, J.; Jansen, K.M.B.; Benedictus, R. Kinetic and thermo-viscoelastic characterisation of the epoxy adhesive in GLARE. Compos. Struct. 2015, 124, 19-28. [CrossRef]

63. Capehart, T.W.; Hamid, G.K.; Taher, A. Cure Simulation of Thermoset Composite Panels. J. Compos. Mater. 2007, 41, 1339-1360. [CrossRef]

64. Ersoy, N.; Tugutlu, M. Cure kinetics modeling and cure shrinkage behavior of a thermosetting composite. Polym. Eng. Sci. 2010, 50, 84-92. [CrossRef]

65. Ramos, J.A.; Pagani, N.; Riccardi, C.C.; Borrajo, J.; Goyanes, S.N.; Mondragon, I. Cure kinetics and shrinkage model for epoxy-amine systems. Polymer 2005, 46, 3323-3328. [CrossRef]

66. Abouhamzeh, M.; Sinke, J.; Jansen, K.M.B.; Benedictus, R. Closed form expression for residual stresses and warpage during cure of composite laminates. Compos. Struct. 2015, 133, 902-910. [CrossRef]

67. Abouhamzeh, M.; Sinke, J.; Benedictus, R. A large displacement orthotropic viscoelastic model for manufacturing-induced distortions in Fibre Metal Laminates. Compos. Struct. 2019, 209, 1035. [CrossRef]

68. Russell, J.D. Cure shrinkage of thermoset composites. Sampe Q. Soc. Adv. Mater. Process Eng. 1993, 24, 28.

69. Jansen, K.M.B.; Hawryluk, M.; Gromala, P. Cure dependent characterisation of moulding compounds. In Proceedings of the 2011 12th International Conference on Thermal, Mechanical and Multi-Physics Simulation and Experiments in Microelectronics and Microsystems, Linz, Austria, 18-20 April 2011; pp. 1-6.

70. Nawab, Y.; Boyard, N.; Sobotka, V.; Casari, P.; Jacquemin, F. Measurement and modelling of chemical shrinkage of thermoset composites. In Key Engineering Materials; Trans Tech Publications: New York, NY, USA, 2012; Volume 504, pp. 1129-1134.

71. Sadeghinia, M.; Jansen, K.M.B.; Ernst, L.J. Characterization and modeling the thermo-mechanical cure-dependent properties of epoxy molding compound. Int. J. Adhes. Adhes. 2012, 32, 82-88. [CrossRef]

72. Mergheim, J.; Possart, G.; Steinmann, P. Modelling and computation of curing and damage of thermosets. Comput. Mater. Sci. 2012, 53, 359-367. [CrossRef] 
73. De Vreugd, J.; Jansen, K.M.B.; Ernst, L.J.; Pijnenburg, J.A.C.M. Modelling of viscoelastic properties of a curing adhesive. WIT Trans. Eng. Sci. 2007, 57, 241.

74. Ernst, L.J.; Jansen, K.M.B.; Saraswat, M.; Van 'T Hof, C.; Zhang, G.Q.; Yang, D.G.; Bressers, H.J.L. Fully cure-dependent modelling and characterization of EMC's with application to package warpage simulation. In Proceedings of the 2006 7th International Conference on Electronic Packaging Technology, Shanghai, China, 26-29 August 2007; pp. 23-27.

75. Jansen, K.M.B.; De Vreugd, J.; Ernst, L.J. Analytical estimate for curing-induced stress and warpage in coating layers. J. Appl. Polym. Sci. 2012, 126, 1623-1630. [CrossRef]

76. Caminero, M.A.; Pavlopoulou, S.; Lopez-Pedrosa, M.; Nicolaisson, B.G.; Pinna, C.; Soutis, C. Analysis of adhesively bonded repairs in composites: Damage detection and prognosis. Compos. Struct. 2013, 95, 500-517. [CrossRef]

77. Patel, J.P.; Xiang, Z.G.; Hsu, S.L.; Schoch, A.B.; Carleen, S.A.; Matsumoto, D. Characterization of the crosslinking reaction in high performance adhesives. Int. J. Adhes. Adhes. 2017, 78, 256-262. [CrossRef]

78. Patel, J.P.; Xiang, Z.G.; Hsu, S.L.; Schoch, A.B.; Carleen, S.A.; Matsumoto, D. Path to achieving molecular dispersion in a dense reactive mixture. J. Polym. Sci. Part B Polym. Phys. 2015, 53, 1519-1526. [CrossRef]

79. Patel, J.P.; Deshmukh, S.; Zhao, C.; Wamuo, O.; Hsu, S.L.; Schoch, A.B.; Carleen, S.A.; Matsumoto, D. An analysis of the role of nonreactive plasticizers in the crosslinking reactions of a rigid resin. J. Polym. Sci. Part B Polym. Phys. 2017, 55, 206-213. [CrossRef]

80. De Vreugd, J.; Jansen, K.M.; Ernst, L.J.; Bohm, C. Prediction of cure induced warpage of micro-electronic products. Microelectron. Reliab. 2010, 50, 910-916. [CrossRef]

81. Stauffer, D. Introduction to Percolation Theory; Taylor and Francis: London, UK, 1985.

82. Adolf, D.; Martin, J.E. Calculation of stresses in crosslinking polymers. J. Compos. Mater. 1996, 30, 13-34. [CrossRef]

83. Adolf, D.B.; Chambers, R.S. A thermodynamically consistent, nonlinear viscoelastic approach for modeling thermosets during cure. J. Rheol. 2007, 51, 23-50. [CrossRef]

84. Gao, J.; Li, L.; Deng, Y.; Gao, Z.; Xu, C.; Zhang, M. Study of gelation using differential scanning calorimetry (DSC). J. Therm. Anal. 1997, 49, 303-310. [CrossRef]

85. Menczel, J.D.; Prime, R.B. (Eds.) Thermal Analysis of Polymers: Fundamentals and Applications; John Wiley \& Sons: Hoboken, NJ, USA, 2009.

86. Hayaty, M.; Beheshty, M.H.; Esfandeh, M. A new approach for determination of gel time of a glass/epoxy prepreg. J. Appl. Polym. Sci. 2011, 120, 1438-1489. [CrossRef]

87. Bilyeu, B.; Brostow, W.; Menard, K.P. Separation of gelation from vitrification in curing of a fiber-reinforced epoxy composite. Polym. Compos. 2002, 23, 1111-1119. [CrossRef]

88. Jakobsen, J.; Andreasen, J.H.; Thomsen, O.T. A comparison of gel point for a glass/epoxy composite and a neat epoxy material during isothermal curing. J. Compos. Mater. 2014, 48, 917-929. [CrossRef]

89. Xie, M.; Zhang, Z.; Gu, Y.; Li, M.; Su, Y. A new method to characterize the cure state of epoxy prepreg by dynamic mechanical analysis. Thermochim. Acta 2009, 487, 8-17. [CrossRef]

90. Stark, W.; Jaunich, M.; McHugh, J. Carbon-fibre epoxy prepreg (CFC) curing in an autoclave analogue process controlled by Dynamic Mechanical Analysis (DMA). Polym. Test. 2013, 32, 1487-1494. [CrossRef]

91. Stark, W. Investigation of the curing behaviour of carbon fibre epoxy prepreg by Dynamic Mechanical Analysis DMA. Polym. Test. 2013, 32, 231-239. [CrossRef]

92. Abouhamzeh, M.; Sinke, J.; Jansen, K.M.B.; Benedictus, R. A new procedure for thermo-viscoelastic modelling of composites with general orthotropy and geometry. Compos. Struct. 2015, 153, 871-877. [CrossRef]

93. Abouhamzeh, M.; Sinke, J.; Jansen, K.M.B.; Benedictus, R. Thermo-viscoelastic analysis of GLARE. Compos. Part B Eng. 2016, 99, 1-8. [CrossRef]

94. Jansen, K.M.B.; Wang, L.; Van't Hof, C.; Ernst, L.J.; Bressers, H.J.L.; Zhang, G.Q. Cure, temperature and time dependent constitutive modeling of moulding compounds. In Proceedings of the 5th International Conference on Thermal and Mechanical Simulation and Experiments in Microelectronics and Microsystems, Brussels, Belgium, 10-12 May 2004; p. 581.

95. Jansen, K.M.B.; Wang, L.; Yang, D.G.; Van't Hof, C.; Ernst, L.J.; Bressers, H.J.L.; Zhang, G.Q. Constitutive modeling of moulding compounds [electronic packaging applications]. In Proceedings of the 54th Electronic Components and Technology Conference, Las Vegas, NV, USA, 4 June 2004; pp. 890-894. 
96. Van't Hof, C.; Wisse, G.; Ernst, L.J.; Jansen, K.M.B.; Yang, D.G.; Zhang, G.Q.; Bressers, H.J.L. A novel tool for cure dependent viscoelastic characterization of packaging polymers. In Proceedings of the 5th International Conference on Thermal and Mechanical Simulation and Experiments in Microelectronics and Microsystems, Brussels, Belgium, 10-12 May 2004; pp. 385-390.

97. O'Brien, D.J.; Mather, P.T.; White, S.R. Viscoelastic properties of an epoxy resin during cure. J. Compos. Mater. 2001, 35, 883-904. [CrossRef]

98. Kim, Y.K.; White, S.R. Stress relaxation behavior of 3501-6 epoxy resin during cure. Polym. Eng. Sci. 1996, 36, 2852-2862. [CrossRef]

99. Wang, H.B.; Yang, Y.G.; Yu, H.H.; Sun, W.M.; Zhang, Y.H.; Zhou, H.W. Assessment of residual stresses during cure and cooling of epoxy resins. Polym. Eng. Sci. 1995, 23, 1895-1898. [CrossRef]

100. Lange, J.; Toll, S.; Månson, J.A.E.; Hult, A. Residual stress build-up in thermoset films cured below their ultimate glass transition temperature. Polymer 1997, 38, 809-815. [CrossRef]

101. Lange, J.; Toll, S.; Månson, J.A.E.; Hult, A. Residual stress build-up in thermoset films cured above their ultimate glass transition temperature. Polymer 1995, 36, 3135-3141. [CrossRef]

102. Zhang, J.; Xu, Y.; Huang, P. Effect of cure cycle on temperature/degree of cure field and hardness for epoxy resin. E-Polymers 2010, 10. [CrossRef]

103. Zhang, J.; Xu, Y.C.; Huang, P. Effect of cure cycle on curing process and hardness for epoxy resin. Express Polym. Lett. 2009, 3, 534-541. [CrossRef]

104. Liebl, C.; Johlitz, M.; Yagimli, B.; Lion, A. Three-dimensional chemo-thermomechanically coupled simulation of curing adhesives including viscoplasticity and chemical shrinkage. Comput. Mech. 2012, 49, 603-615. [CrossRef]

105. Yang, D.G.; Jansen, K.M.B.; Ernst, L.J.; Zhang, G.Q.; Van Brief, W.D.; Bressers, H.J.L. Modeling of cure-induced warpage of plastic IC packages. In Proceedings of the 5th International Conference on Thermal and Mechanical Simulation and Experiments in Microelectronics and Microsystems, Brussels, Belgium, 10-12 May 2004.

106. Yang, D.G.; Jansen, K.M.B.; Ernst, L.J.; Zhang, G.Q.; Van Brief, W.D.; Bressers, H.J.L.; Fan, X.J. Prediction of process-induced warpage of IC packages encapsulated with thermosetting polymers. In Proceedings of the 54th Electronic Components and Technology Conference, Las Vegas, NV, USA, 4 June 2004.

107. Yang, D.G.; Jansen, K.M.B.; Wang, L.G.; Ernst, L.J.; Zhang, G.Q.; Bressers, H.J.L.; Fan, X. Micromechanical modeling of stress evolution induced during cure in a particle-filled electronic packaging polymer. IEEE Trans. Compon. Packag. Technol. 2004, 27, 676-683. [CrossRef]

108. Yang, D.G.; Jansen, K.M.; Ernst, L.J.; Zhang, G.Q.; Van Driel, W.D.; Bressers, H.J.L.; Janssen, J.H.J. Numerical modeling of warpage induced in QFN array molding process. Microelectron. Reliab. 2007, 47, 310-318. [CrossRef]

109. Van't Hof, C.; Jansen, K.M.; Wisse, G.; Ernst, L.J.; Yang, D.G.; Zhang, G.Q.; Bressers, H.J.L. Novel shear tools for viscoelastic characterization of packaging polymers. Microelectron. Reliab. 2007, 47, 240-247. [CrossRef]

110. Sadeghinia, M.; Jansen, K.M.; Ernst, L.J. Characterization of the viscoelastic properties of an epoxy molding compound during cure. Microelectron. Reliab. 2012, 52, 1711-1718. [CrossRef]

111. Jansen, K.M.B.; Qian, C.; Ernst, L.J.; Bohm, C.; Kessler, A.; Preu, H.; Stecher, M. Kinetic characterisation of molding compounds. In Proceedings of the 2007 International Conference on Thermal, Mechanical and Multi-Physics Simulation Experiments in Microelectronics and Micro-Systems, London, UK, 16-18 April 2007; pp. 1-5.

112. De Vreugd, J.; Jansen, K.M.B.; Ernst, L.J.; Bohm, C.; Kessler, A.; Preu, H. Effects of molding compound cure on warpage of electronic packages. In Proceedings of the 2008 10th Electronics Packaging Technology Conference, Singapore, 9-12 December 2008; pp. 675-682.

113. Jansen, K.M.B.; Qian, C.; Ernst, L.J.; Bohm, C.; Kessler, A.; Preu, H.; Stecher, M. Characterization and modeling of molding compound properties during cure. In Proceedings of the EuroSimE 2008-International Conference on Thermal, Mechanical and Multi-Physics Simulation and Experiments in Microelectronics and Micro-Systems, Breisgau, Germany, 20-23 April 2008; pp. 1-4.

114. Jansen, K.M.; Öztürk, B. Warpage estimation of a multilayer package including cure shrinkage effects. IEEE Trans. Compon. Packag. Manuf. Technol. 2013, 3, 459-466. [CrossRef]

115. Liu, C.; Shi, Y. An improved analytical solution for process-induced residual stresses and deformations in flat composite laminates considering thermo-viscoelastic effects. Materials 2018, 10, 2506. [CrossRef] [PubMed] 
116. Peeters, L.J.B.; Powell, P.C.; Warnet, L. Thermally-induced shapes of unsymmetric laminates. J. Compos. Mater. 1996, 30, 603-626. [CrossRef]

117. Albert, C.; Fernlund, G. Spring-in and warpage of angled composite laminates. Compos. Sci. Technol. 2002, 62, 1895-1912. [CrossRef]

118. Sun, L.; Pang, S.S.; Sterling, A.M.; Negulescu, I.I.; Stubblefield, M.A. Dynamic modeling of curing process of epoxy prepreg. J. Appl. Polym. Sci. 2002, 86, 1911-1923. [CrossRef]

119. Bapanapalli, S.K.; Smith, L.V. A linear finite element model to predict processing-induced distortion in FRP laminates. Compos. PART A Appl. Sci. Manuf. 2005, 36, 1666-1674. [CrossRef]

120. Jung, W.K.; Kim, B.; Won, M.S.; Ahn, S.H. Fabrication of radar absorbing structure (RAS) using GFR-nano composite and spring-back compensation of hybrid composite RAS shells. Compos. Struct. 2006, 75, 571-576. [CrossRef]

121. Capehart, T.W.; Muhammad, N.; Kia, H.G. Compensating thermoset composite panel deformation using corrective molding. J. Compos. Mater. 2007, 41, 1675-1701. [CrossRef]

122. Jung, W.K.; Chu, W.S.; Ahn, S.H.; Won, M.S. Measurement and compensation of spring-back of a hybrid composite beam. J. Compos. Mater. 2007, 41, 851-864. [CrossRef]

123. Ersoy, N.; Garstka, T.; Potter, K.; Wisnom, M.R.; Porter, D.; Stringer, G. Modelling of the spring-in phenomenon in curved parts made of a thermosetting composite. Compos. PART A Appl. Sci. Manuf. 2010, 41, 410-418. [CrossRef]

124. Ersoy, N.; Potter, K.; Wisnom, M.R.; Clegg, M.J. Development of spring-in angle during cure of a thermosetting composite. Compos. PART A Appl. Sci. Manuf. 2005, 36, 1700-1706. [CrossRef]

125. Magniez, K.; Vijayan, A.; Finn, N. Apparent volumetric shrinkage study of RTM6 resin during the curing process and its effect on the residual stresses in a composite. Polym. Eng. Sci. 2012, 52, 346-351. [CrossRef]

126. Abdelal, G.F.; Robotham, A.; Cantwell, W. Autoclave cure simulation of composite structures applying implicit and explicit FE techniques. Int. J. Mech. Mater. Des. 2013, 9, 55-63. [CrossRef]

127. Tavakol, B.; Roozbehjavan, P.; Ahmed, A.; Das, R.; Joven, R.; Koushyar, H.; Rodriguez, A.; Minaie, B. Prediction of residual stresses and distortion in carbon fiber-epoxy composite parts due to curing process using finite element analysis. J. Appl. Polym. Sci. 2013, 28, 941-950. [CrossRef]

128. Hagenbeek, M. Characterisation of Fibre Metal Laminates under Thermo-mechanical Loadings. Ph.D. Thesis, Delft University of Technology, Delft, The Netherlands, 2005.

129. Asundi, A.; Choi, A.Y. Fiber metal laminates: An advanced material for future aircraft. J. Mater. Process. Technol. 1997, 63, 384-394. [CrossRef]

130. Alderliesten, R.C. Fatigue Crack Propagation and Delamination Growth in Glare. Ph.D. Thesis, Delft University of Technology, Delft, The Netherlands, 2005.

131. Homan, J.J. Fatigue initiation in fibre metal laminates. Int. J. Fatigue 2006, 28, 366-374. [CrossRef]

132. Sinke, J. Development of fibre metal laminates: Concurrent multi-scale modeling and testing. J. Mater. Sci. 2006, 41, 6777-6788. [CrossRef]

133. Alderliesten, R.; Benedictus, R. Fiber/metal composite technology for future primary aircraft structures. J. Aircr. 2008, 45, 1182-1189. [CrossRef]

134. Tekıner, Z. An experimental study on the examination of springback of sheet metals with several thicknesses and properties in bending dies. J. Mater. Process. Technol. 2004, 145, 109-117. [CrossRef]

135. Ghouati, O.; Joannic, D.; Gelin, J.C. Optimisation of process parameters for the control of springback in deep drawing. In Proceedings of the NUMIFORM 98: Sixth International Conference on Numerical Methods in Industrial Forming Processes, Enschede, The Netherlands, 22-25 June 1998; pp. 819-824.

136. Lingbeek, R.; Huetink, J.; Ohnimus, S.; Petzoldt, M.; Weiher, J. The development of a finite elements based springback compensation tool for sheet metal products. J. Mater. Process. Technol. 2005, 169, 115-125. [CrossRef]

137. Hu, J.; Chung, K.; Li, X.X.; Park, T.; Zhou, G.F.; Yao, R. An automatic spring-back compensation method in die design based on a genetic algorithm. Met. Mater. Int. 2011, 17, 527-533. [CrossRef]

138. Li, X.X.; Hu, J.; Chung, K.; Zhou, G.F.; Yao, R. 8th International Conference and Workshop on Numerical Simulation of 3d Sheet Metal Forming Processes. In American Institute of Physics Conference Series; Web of Science Group: College Park, MD, USA, 2011; p. 1092.

139. Lee, J.W.; Lee, M.G.; Barlat, F. Finite element modeling using homogeneous anisotropic hardening and application to spring-back prediction. Int. J. Plast. 2012, 29, 13-41. [CrossRef] 
140. Kim, S.Y.; Choi, W.J.; Park, S.Y. Spring-back characteristics of fiber metal laminate (GLARE) in brake forming process. Int. J. Adv. Manuf. Technol. 2007, 32, 445-451. [CrossRef]

141. Krimbalis, P.P.; Poon, C.; Fawaz, Z.; Behdinan, K. On the prediction of induced residual stresses in fibre metal laminates. In Proceedings of the 7th Joint Canada-Japan Workshop on Composites, Fujisawa, Japan, 28-31 July 2008; pp. 125-132.

142. Hofslagare, P. Residual stress measurement on fibre-metal-laminates. J. Neutron Res. 2003, 11, $215-220$. [CrossRef]

143. Şen, I.; Alderliesten, R.C.; Benedictus, R. Design optimisation procedure for fibre metal laminates based on fatigue crack initiation. Compos. Struct. 2015, 120, 275-284. [CrossRef]

144. Şen, I.; Alderliesten, R.C.; Benedictus, R. Lay-up optimisation of fibre metal laminates based on fatigue crack propagation and residual strength. Compos. Struct. 2015, 124, 77-84. [CrossRef]

145. Abouhamzeh, M.; Sinke, J.; Benedictus, R. On the prediction of cure-process shape deviations in fibre metal laminates. J. Compos. Mater. 2015, 49, 1705-1716. [CrossRef]

146. Abouhamzeh, M.; Sinke, J.; Benedictus, R. Investigation of curing effects on distortion of fibre metal laminates. Compos. Struct. 2015, 122, 546-552. [CrossRef]

147. Abouhamzeh, M.; Sinke, J.; Benedictus, R. On the investigation of residual stress and shape deviation development in manufacturing of GLARE. In Proceedings of the ECCM16-16th European Conference on Composite Materials, Seville, Spain, 22-26 June 2014.

(C) 2019 by the authors. Licensee MDPI, Basel, Switzerland. This article is an open access article distributed under the terms and conditions of the Creative Commons Attribution (CC BY) license (http://creativecommons.org/licenses/by/4.0/). 